\title{
The heterogeneity of disruptive behavior disorders - implications for neurobiological research and treatment
}

\author{
Christina Stadler ${ }^{1}{ }^{*}$, Fritz Poustka ${ }^{1}$ and Philipp Sterzer ${ }^{2}$ \\ 1 Department of Child and Adolescent Psychiatry, Johann Wolfgang Goethe University, Frankfurt am Main, Germany \\ 2 Department of Psychiatry, Charité Campus Mitte, Berlin, Germany
}

Edited by:

Christina S. Barr, National Institutes of Health, USA

\section{Reviewed by:}

Essi Viding, University College London, UK

Stephanie van Goozen, Cardiff

University, UK

Stephane A. De Brito, University

College London, UK

\section{${ }^{*}$ Correspondence:}

Christina Stadler, Department of Child

and Adolescent Psychiatry,

Schaffhauserrheinweg 55, CH-4058

Basel, Switzerland.

e-mail:christina.stadler@upkbs.ch
Disruptive behavior disorders (DBDs) are reflected by a great variety of symptoms ranging from impulsive-hot-tempered quarrels to purposeful and goal-directed acts of cruelty. A growing body of data indicates that there are neurobiological factors that increase the risk for developing DBDs. In this review, we give a broad overview of recent studies investigating physiological, neural, genetic factors, and specific neurotransmitter systems. We also discuss the impact of psychosocial risk and consider the effects of gene-environment interactions. Due to the heterogeneity of DBDs, it is concluded that specific subtypes of disruptive behavior should be considered both in terms their biological basis and in regard to specific treatment needs.

Keywords: neurobiology, aggression, conduct disorder, disruptive behaviour disorder, review, research, intervention

\section{INTRODUCTION}

The purpose of this manuscript is to selectively review the literature on neurobiological factors that are associated with conduct disorder and that predispose to developing and maintaining aggressive and antisocial behavior.

Conduct disorder (CD) and oppositional defiant disorder (ODD) are subsumed under disruptive behavior disorders (DBDs) in the DSM classification system (American Psychiatric Association, 1994). They are characterized by repetitive and chronic aggressive and antisocial behavior that has a variety of implications such as school refusal, social communication problems, and legal involvement. CD is classified as "mild" if there are few, if any, conduct problems in excess of those required for diagnosis and if these cause only minor harm to others (e.g., lying, truancy and breaking parental rules). It is classified as "moderate" if the number of conduct problems and effect on others are intermediate between "mild" and "severe." "Severe" CD is diagnosed if many conduct problems exist in excess of those required for diagnosis, or if the conduct problems cause considerable harm to others or property (e.g., rape, assault, mugging, breaking and entering) (American Psychiatric Association, 1994). ODD is generally considered a milder disorder than $\mathrm{CD}$, but is also associated with functional impairment, and in some cases it progresses to $\mathrm{CD}$. While ODD is treated as a subtype of CD in ICD-10 (World Health Organisation, 2007), in DSM-IV, CD and ODD are specified as separate disorders with exclusive symptom lists: 3 of 15 symptoms are required for a diagnosis of $\mathrm{CD}$, and four of eight symptoms are required for a diagnosis of ODD (see Table 1).

The prevalence of DBDs is relatively high: $2 \%$ for $\mathrm{CD}$ and $3.2 \%$ for ODD. Boys seem to be more affected than girls. However, this can be due to the fact that the existing classification systems are more suitable to identify aggressive and antisocial behavior in boys than in girls (Lahey et al., 1999).
There is a high-risk group starting with aggressive behavior at a particularly early age. This subtype of CD is likely to take a nonfavorable outcome and is characterized by an elevated biological risk (Moffitt et al., 2008).

Conduct disorder is not a unitary disorder. This is recognized to some extent in the DSM-IV-TR by subdividing CD into Childhoodand Adolescent-Onset subtypes (those emerging before and after age 10, respectively) (American Psychiatric Association, 1994). But the heterogeneity of individuals with $\mathrm{CD}$ is also reflected by a great variety of symptoms ranging from impulsive hot-tempered quarrels to acts of cruelty to animals or stealing; and by the extent of comorbidity (e.g., attention deficit disorder, depression, anxiety disorders, learning difficulties, posttraumatic stress disorder, etc.). Since the clinical population of disruptive children varies substantially with regard to biological, environmental, and social cognitive risk factors as well as comorbidity, these factors have to be considered carefully in order to better understand the etiology of DBDs (Raine, 2002a). Despite a strong continuity in aggressive behavior between childhood, adolescence and adult life, the complexity in regard to risk and protective individual und environmental factors as well as conceptual models (aggression subtypes) should guide research to further the understanding of factors that enhance the course and the stability of disruptive behavior.

\section{SUBTYPES OF AGGRESSION}

Due to the symptom heterogeneity of $\mathrm{CD}$, the investigation of the underlying neurobiological pathways might benefit from a systematic differentiation between subtypes of aggressive behavior (see Table 2). The domain of aggression and antisocial behavior can be subdivided in various ways (Hinshaw and Lee, 2003). A key distinction is between reactive (affective, impulsive or defensive) and proactive (instrumental and premeditated) aggression, as these two types of aggression might differ in their biological basis (Crick and Dodge, 1996; Kempes et al., 2005). 
Table 1 | Nosological classification.

\section{OPPOSITIONAL DEFIANT DISORDER (ODD)}

Oppositional Defiant Disorder (ODD) consists of a pattern of negativistic, hostile, and defiant behavior lasting at least 6 months, during which four (or more) of the following behaviors are present:

- Often loses temper

- Often argues with adults

- Often actively defies or refuses to comply with adults' requests or rules

- Often deliberately annoys people

- Often blames others for his or her mistakes or misbehavior

- Is often touchy or easily annoyed by others

- Is often angry and resentful

- Is often spiteful or vindictive

Each of the above is only considered diagnostic if the behavior occurs more frequently than is typically observed in children of comparable age and developmental level and if the behavior causes clinically significant impairment in social, academic, or occupational functioning.

Oppositional Defiant disorder is not diagnosed if the behaviors occur exclusively during the course of a Psychotic or Mood Disorder or if Conduct Disorder is diagnosed.

\section{CONDUCT DISORDER}

The DSM-IV categorizes conduct disorder behaviors into four main groupings: (a) aggressive conduct that causes or threatens physical harm to other people or animals, (b) non-aggressive conduct that causes property loss or damage, (c) deceitfulness or theft, and (d) serious violations of rules. Conduct Disorder consists of a repetitive and persistent pattern of behaviors in which the basic rights of others or major age-appropriate norms or rules of society are violated. Typically there would have been three or more of the following behaviors in the past 12 months, with at least one in the past 6 months:

Aggression to people and animals

- often bullies, threatens, or intimidates others

- often initiates physical fights

- has used a weapon that can cause serious physical harm to others (e.g., a bat, brick, broken bottle, knife, gun)

- has been physically cruel to people

- has been physically cruel to animals

- has stolen while confronting a victim (e.g., mugging, purse snatching, extortion, armed robbery)

- has forced someone into sexual activity

Destruction of property

has deliberately engaged in fire setting with the intention of causing serious damage

has deliberately destroyed others' property (other than by fire setting)

Deceitfulness or theft

has broken into someone else's house, building, or car

often lies to obtain goods or favors or to avoid obligations (i.e., "cons" others)

has stolen items of non-trivial value without confronting a victim (e.g., shoplifting, but without breaking and entering; forgery)

Serious violations of rules

often stays out at night despite parental prohibitions, beginning before age 13 years

has run away from home overnight at least twice while living in parental or parental surrogate home (or once without returning for a lengthy period) is often truant from school, beginning before age 13 years

Reactive aggression is triggered by a frustrating or threatening event and is often accompanied by anger. The aggressive act is initiated without regard for any potential goal (e.g., gaining the victim's possessions). In contrast, proactive aggression is purposeful and goal-directed (e.g., to obtain the victim's possessions, not usually to inflict pain) and involves a minimal level of physiological arousal. Since proactive aggression is driven by the anticipation of reward, it is under the control of positive reinforcement, either directly or vicariously (i.e., through modeling). Reactive aggression is instead under the control of negative reinforcement, when successful in turning off the provocation of the threat that triggered aggression in the first place (Vitaro and Brendgen, 2005).

This two-factor model has been criticized, mainly due to some difficulty in characterizing the nature of specific human aggressive episodes (Bushman and Anderson, 2001). However, considering that aggressive subtypes are not mutually exclusive, a considerable amount of data supports the existence of two relatively separable populations of aggressive individuals: individuals who present with mostly reactive aggression and those who present with high levels of mostly proactive and some reactive aggression: Besides exploratory and confirmatory factor analyses (e.g., Baker et al., 2008) further evidence supporting the distinction between reactive and proactive aggression has been provided by studies showing different correlates of the two forms of aggression. Reactive aggression is related to earlier physical abuse, early onset of attention problems and impulsiveness (Dodge et al., 1997; Barry et al., 2007), peer rejection or victimization (Lamarche et al., 2007; Salmivalli and Helteenvuori, 2007). In contrast, proactive aggression is linked to highly heritable psychopathy-like callous-unemotional traits (Raine et al., 2006) and later delinquent behavior (Vitaro et al., 1998; Brendgen et al., 2001). 
Table 2 | Subtypes of aggressive behavior.

\begin{tabular}{|c|c|c|}
\hline & Proactive & Reactive \\
\hline Aim & Purposeful and goal-directed & Not goal-directed \\
\hline Behavioral characteristic & Instrumental, controlled & Impulsive, deficient control mechanisms \\
\hline Time perspective & Long, planned & Sudden outburst \\
\hline Maintenance & $\begin{array}{l}\text { Positive reinforcement (aggressive behavior is reinforced } \\
\text { through its benefit) }\end{array}$ & $\begin{array}{l}\text { Negative reinforcement (provocation/threat is } \\
\text { reduced through aggressive behavior) }\end{array}$ \\
\hline Emotional reactivity & $\begin{array}{l}\text { Callous-unemotional, low empathy lack of emotion, lack } \\
\text { of guilt }\end{array}$ & Hot-tempered (anger, fear to provocation) \\
\hline $\begin{array}{l}\text { Physiological reactivity (heart rate, } \\
\text { electrodermal activity, cortisol) }\end{array}$ & Low reactivity & High reactivity \\
\hline Neural correlates & Low responsiveness of the amygdale, insular cortex & Deficient activation of inhibiting neural structures \\
\hline Responsible transmitter system & Reduced norepinephrine function & Reduced serotonin function \\
\hline Social cognitive processing & $\begin{array}{l}\text { Deficient response access and response decision (lack in } \\
\text { conscience development) }\end{array}$ & $\begin{array}{l}\text { Deficient social information processing (hostile } \\
\text { attribution bias) }\end{array}$ \\
\hline
\end{tabular}

Proactive forms of aggression seem specific for CD or antisocial behavior disorder, whereas elevated levels of reactive aggression are found in many disorders, e.g., depression, anxiety, bipolar disorders and posttraumatic stress disorders (Blair, 2003).

There is increasing evidence that stability of aggressive behavior varies between subtypes: According to a longitudinal twin study, reactive aggression decreases over time, while proactive aggression remains stable. Longitudinal analyses have indicated that the stable variance in reactive aggression is mainly due to genetic and non-shared environmental influences, whereas the stable individual differences in proactive aggression are primarily genetically mediated (Tuvblad et al., 2009). Thus, there is some indication that these subtypes are mediated through different psychopathological pathways and different developmental trajectories (Murray-Close and Strove, 2009). One of the most consistent neurobiological findings is reduced serotonergic functioning, mainly in reactive aggression, and reduced physiological arousal particularly in proactive aggression (Kempes et al., 2005). Hence, the presence of genes associated with deficient serotonergic functioning may predispose a child to angry outbursts of reactive behavior when faced with provocation or threat. In contrast, a biological/genetic predisposition to physiological hyporeactivity may render a child less sensitive to stressors and to the aversive consequences of aggressive behavior (i.e., punishment), thus increasing the risk for proactive aggressive behavior.

To understand the different psychopathological pathways of aggressive and antisocial behavior, it seems also important to investigate those processes which are necessary for social learning. From a neuro-scientific point of view, one should therefore ask which biological and psychosocial factors hamper the development and refinement of control and inhibition processes (e.g., to inhibit hot-tempered impulses), adequate emotion processing (to perceive and interpret emotional cues) or the development of empathy (e. g. perspective taking, to feel with others).

\section{PHYSIOLOGICAL CORRELATES}

Psychophysiological research has provided substantial evidence suggesting that decreased autonomic baseline arousal, e.g., low resting heart rate and low resting electrodermal activity as well as low orienting reaction, accelerated habituation and autonomic hyporesponsiveness to punishment cues are associated with aggressive and antisocial behavior in children and adolescents (for a review see Lorber, 2004; Ortitz and Raine, 2004). Children with low resting heart rate appear to be genetically predisposed toward disruptive behavior problems (Baker et al., 2009). On the other hand, an enhanced heart rate and skin conductance response was found especially in those children exhibiting predominantly reactive aggression (Lorber, 2004).

This line of research has further revealed that autonomic hyporesponsiveness is of prognostic value. Autonomic underarousal and low autonomic responses in 15-year-old boys are predictive of adult criminal behavior, particularly in boys without psychosocial disadvantages, while heightened autonomic responsiveness appears to be a protective factor against criminal outcome in high-risk male adolescents (Raine et al., 1990, 1995, 1997). Even at the age of 3 years, poor fear conditioning is predictive of future criminal behavior in adulthood (Gao et al., 2010)

Herpertz et al. $(2001,2003)$ have found decreased electrodermal responses and accelerated habituation to orienting and startling tones specific for children with $\mathrm{CD}$, irrespective of comorbid ADHD. In addition, these children also exhibited a generalized deficit in autonomic responsivity when exposed to pictures of unpredictable affective quality (Herpertz et al., 2005).

The finding of low autonomic arousal to negative and aversive stimuli as well as an impaired recognition of emotional cues like facial expression in children with antisocial behavior and callousunemotional traits suggests a link between the disposition of aggression and a failure of emotion processing in this subgroup (Blair et al., 2001; Loney et al., 2003). The propensity for aggressive behavior may be associated with a low threshold for activating negative emotions like fear, empathy or guilt. The lack of emotional and autonomic responsiveness may result in a failure to develop behavioral strategies to avoid negative consequences, thus affecting adequate social and moral learning processes (Blair, 2006). In addition, the ability to detect an affective state of another person is considered a precursor of empathy. It has been shown that there is a strong inverse correlation between the ability to empathize with the emotional experiences of others and self-reported acts of 
delinquent behavior (Carr and Lutjemeier, 2005). Poor empathic responding, particularly reduced responsiveness to the fear and sadness of others, has been linked to heightened levels of proactive aggression (Blair, 2001).

Patrick and Bernat (2009) have reviewed findings on electrocortical response measures (EEG/ERP) in individuals exhibiting aggressive behavior: It has been repeatedly shown that impulsive/ reactive-aggressive individuals show an enhanced cortical slow-wave activity in brain areas including frontal and temporal regions, especially in the delta frequency range (Volavka, 1990). Furthermore, particularly among individuals exhibiting impulsive aggression, a reduced amplitude of the P300 response is a consistent finding. Although, a reduced P300 appears to be a general indicator of externalizing behavior characteristic for various disorders, indicating a dispositional vulnerability to impulse control problems (Krueger et al., 2002) it has been proposed that this electrophysiological pattern differs from proactive aggression and callous-unemotional traits (Patrick et al., 1997; Frick and White, 2008).

\section{STRUCTURAL AND FUNCTIONAL BRAIN CORRELATES}

Emotion processing in the human brain involves a complex network of brain regions including the amygdala, orbital frontal cortex, cingulate cortex, insular cortex, and other interconnected regions (Dolan, 2002).

In adults with aggressive and antisocial behavior, a number of brain imaging studies have demonstrated structural abnormalities in these brain regions (for a review see Plodowski et al., 2009). Prefrontal gray matter has repeatedly been found to be reduced in adult antisocial individuals and is inversely related to psychopathic behavior (Raine et al., 2000; Yang et al., 2005). Interestingly, the study by Yang et al. (2005) revealed that unsuccessful psychopaths, but not successful psychopaths, had a significant reduction in prefrontal gray matter volume compared with control subjects. The prefrontal structural deficit may underlie low autonomic arousal, poor fear conditioning and reduced stress responsivity in antisocial, psychopathic behavior (Raine et al., 2000; Kruesi et al., 2004). Furthermore, poor fear conditioning is hypothesized to be associated with poor conscience development, as individuals autonomically less responsive to aversive stimuli seem to be unsusceptible to socializing punishment (Raine, 1993).

There is now also evidence for functional and structural brain abnormalities in youths with CD. One study reported a reduction of gray matter volume in right temporal lobe in CD compared to control subjects (Kruesi et al., 2004). Prefrontal volumes in subjects with CD were $16 \%$ smaller than in controls, but the difference did not reach statistical significance. Two recent studies used a voxel-wise method (voxel-based morphometry) to compare gray matter volume CD patients and age-, sex-, and intelligencematched control subjects (Sterzer et al., 2007; Huebner et al., 2008). Both studies reported decreased gray matter volume in mesial temporal lobe structures, including the amygdala, and a significant association of these gray matter deficits with the severity of conduct problems. Orbitofrontal gray matter volume was also found to be reduced (Huebner et al., 2008), in line with previous reports of conduct problems in individuals with early acquired prefrontal lobe damage (Anderson et al., 1999). Sterzer et al. (2007) additionally found a gray matter volume reduction in bilateral anterior insular cortex, which correlated with empathy levels as assessed behaviorally. This finding supports the notion of a crucial involvement of the anterior insula in the experience of empathy (De Vignemont and Singer, 2006). A recent VBM study in a non-clinical sample of boys with conduct problems and callous-unemotional traits reported increased instead of decreased gray matter in orbitofrontal and anterior cingulate cortices (De Brito et al., 2009). This finding was interpreted as a delay in cortical maturation, as the physiological prefrontal age-related gray matter decrease found in normally developing children was not observed in the group of callous-unemotional boys. Despite the obvious differences in sample characteristics between the study by De Brito et al. (2009) and the other two VBM studies by Sterzer et al. (2007) and Huebner et al. (2008), the seemingly opposing results of these studies call for research relating structural brain changes to specific subtypes of aggressive behavior and to potential abnormalities in brain development (Moffitt et al., 2008).

Functional magnetic resonance imaging (fMRI) studies have examined the neural correlates of emotion processing in aggressive and antisocial individuals. In adult psychopaths, functional abnormalities in the amygdala, the OFC, and the anterior cingulate cortex (ACC) have been shown (Kiehl et al., 2001; Veit et al., 2002). The first study on emotion processing in aggressive children and adolescents investigated neural processing of negative affective pictures in a group of boys with CD (Sterzer et al., 2005). This study demonstrated a negative relationship between aggressive behavior and the responsiveness of the left amygdala to strong negative affective pictures. A positive correlation was found with symptoms of anxiety and depression, which are often comorbid features in CD (Loeber et al., 2000). In low-anxious adolescents, however, the reduced responsiveness of the amygdala seems to be a specific characteristic reflecting a neural impairment in the recognition of emotional stimuli as an early substrate of pathological aggression. Whereas a recent study by Herpertz et al. (2008) showed contradictory results, the notion of amygdala hyporeactivity in youths with high levels of aggression was further supported by two fMRI studies by Marsh et al. (2008) and Jones et al. (2009), who found reduced right sided amygdala activation to fearful expressions in children with aggressive conduct problems and callous-unemotional traits compared to children with ADHD and healthy controls. In sum, these results indicate that amygdala hyporesponsiveness might be specifically associated with unemotional, low-anxious coldtempered forms of aggressive behavior. As amygdala function is an important determinant of social interactions at the perceptual level, a reduced responsiveness to affective stimuli is in keeping with current models regarding the mechanisms that underlie deficient social interactions and pathological aggression (Davidson et al., 2000; Dolan, 2002; Blair, 2005).

In addition, viewing of affective pictures was accompanied by a pronounced deactivation in the right dorsal ACC in CD patients compared to controls (Sterzer et al., 2005). This deactivation could reflect an affect-evoked suppression of neural activity during emotional exposure, possibly interfering with cognitive functions that might be crucial in the regulation of emotional behavior. In a follow-up study, the authors probed the relationship between the observed functional neural deficits in ACC and 
specific temperament factors predisposing to DBDs (Stadler et al., 2006). Interestingly, the temperament dimension "novelty seeking" (Cloninger, 1987), which comprises high impulsivity and a quicktempered personality, was a significant predictor for ACC responsiveness to affective pictures. Individuals with high novelty seeking were characterized by deficient behavioral control strategies and a lower level of sociomoral reasoning. The deficient activation in the dorsal ACC of patients with CD might hence be a linking factor between temperament factors, cognitive and emotional processing, and behavioral outcome. In that sense, a close relationship between high novelty seeking and an impaired capacity to cognitively control emotional behavior might underlie the predisposition for the development of DBDs.

Taken together, structural brain imaging and fMRI studies on emotion processing in pathological aggression to date suggest that the disposition to aggressive behavior might originate from an impairment of both the recognition of emotional stimuli and the cognitive control of emotional behavior.

\section{NEUROTRANSMITTER SYSTEMS}

Serotonin (5-hydroxytryptamine, 5-HT) is thought to be one of the most essential central neurotransmitters to inhibit aggression directed against oneself and others. While a wealth of studies in adult and animal research consistently indicate an inverse relationship between central serotonin and indices of aggression and, more specifically, with impulsive behavior and reactive aggression (i.e., Virkunnen et al., 1995), studies in children have yielded conflicting results. Both direct central and indirect peripheral measures of central serotonergic function have been assessed in children with DBDs. In accord with the findings in adults, an inverse correlation between 5-hydroxyindol acetic acid (5-HIAA) in samples of lumbar cerebrospinal fluid (CSF) and aggression was found (Kruesi et al., 1990). Some studies further indicate that low CSF 5-HIAA correlate with poor outcome (Kruesi et al., 1992) and sociability (Constantino and Murphy, 1996; Clarke et al., 1999). One study reported a positive correlation between CSF-5-HIAA and measures of aggression and impulsivity/hyperactivity (Castellanos et al., 1994), but in less aggressive ADHD patients. A useful alternative method of studying the central 5-HT system in a non-invasive way is the rapid tryptophan depletion test (RTD). The ingestion of a tryptophan-free mixture of amino acids significantly reduces plasma tryptophan, the precursor of serotonin, and as a consequence also central 5-HT levels. Up to now, however, this method has barely been used in children and adolescents. First results indicate an inverse relationship between aggressive behavior and experimentally induced low 5-HT levels (Stadler et al., 2007) whereas no relationship between executive functioning and altered 5-HT was found (Le Marquand et al., 1998).

In studies of aggressive children using whole blood serotonin assays, peripheral measures of 5-HT yielded mixed results: Some found increased peripheral 5-HT concentrations in DBDs (i.e., Pliszka et al., 1988; Hughes et al., 1996; Unis et al., 1997) or no differences compared to normal or psychiatric controls (i.e., Rogeness et al., 1982; Cook et al., 1995); others reported a negative correlation (Hanna et al., 1995; Van Goozen et al., 1999) or a decrease of platelet serotonin uptake in CD patients (Stadler et al., 2004; for a review see van Goozen and Fairchild, 2009).
Pharmacological challenge studies that assess 5-HT function by measuring the prolactine PRL) response to the 5-HT release/ reuptake inhibitor fenfluramine (FEN) have yielded contradicting results in children and adolescents: The PRL-FEN response was found to be significantly enhanced in aggressive boys (Halperin et al., 1994), differed between aggressive and non-aggressive boys of young age only (Halperin et al., 1997; Pine et al., 1997), or was found to be unrelated to aggression (Schulz et al., 2001). Those studies detecting a positive correlation of 5-HT with aggression were the ones with the youngest samples (Halperin et al., 1994; Pine et al., 1997). Age may thus be an important factor in explaining these inconsistent results and aggressive behavior may be associated with developmental abnormalities of the 5-HT system: Younger children, who initially have an enhanced prolactin response to fenfluramine probably fail to undergo normal developmental changes in 5-HT function and subsequently have a blunted response (Halperin et al., 1997).

Together, although there are still contradictory results in regard to serotonin functioning, there is evidence to suggest that serotonin is involved, at least in part, in mediating reactive-aggressive components of conduct-disordered behavior. Whereas the inhibition of reactive-aggressive behavior might be more strongly associated with serotonergic processes, other neurotransmitter systems, especially norepinephrine, seem to play a role in other subtypes of aggressive behavior, e.g., proactive aggression. Norepinephrine is involved in mediating the impact of aversive cues in human choice behavior (Rogers et al., 2004a,b). This suggests that reduced levels of norepinephrine, leading to reduced responsiveness to aversive cues, might be related to a heightened risk for proactive aggression. In line with this suggestion, there have been a series of reports suggesting that antisocial behavior is associated with reduced norepinephrine levels (Raine, 1993).

In conclusion, although there are still contradictory results, there is some neurobiological evidence pointing toward a role for the serotonin and/or norepinephrine system in CD. Based on the results discussed above, however, future studies should focus on well-defined subgroups of aggressive individuals (i.e., reactive and proactive aggression) in order to explore the role of neurotransmitters in pathological aggression more closely.

\section{NEUROENDOCRINE CORRELATES}

Hypothalamic-pituitary adrenal (HPA) axis function is an important determinant of interindividual differences in aggressive and antisocial behavior (Van Goozen and Fairchild, 2009). Besides genetic factors involved in the modulation of the HPA-axis reactivity (Wüst et al., 2000; DeRijk et al., 2006), early stress factors (maternal prenatal smoking, maltreatment) might have - due to the brain plasticity of the developing child - an important influence on HPA-axis activity.

Although there are more contradictory results in children and adolescents compared to antisocial adults, it seems that both basal cortisol and cortisol levels during stress could be valuable biological markers of DBD, whereby cortisol levels are inversely related to aggressive behavior (Vanyukov et al., 1993; Van Goozen et al., 1998b, 2000; McBurnett et al., 2000; Pajer et al., 2001; Snoek et al., 2004; Gordis et al., 2006; Pompa et al., 2006; Fairchild et al., 2008). In two longitudinal studies it was shown that a low basal cortisol level 
is predictive of later aggressive behavior. Interestingly, the inverse correlation was more specific for proactive forms of aggression and was not related to affective aggression (McBurnett et al., 2000). This result was recently confirmed by Lopez-Duran et al. (2009) who found higher cortisol reactivity in reactive-aggressive compared to proactive and non-aggressive prepubertal children from a non-clinical sample with an elevated risk for school-age conduct problems. Thus, there is some evidence that increased HPA-axis activity might be specific for the reactive aggression subtype. In line with this hypothesis, Van Goozen et al. (1998b) reported that conduct-disordered children with low levels of anxiety showed a smaller cortisol reaction during a stress situation compared to control children and aggressive children with high levels of anxiety. A positive relationship between anxiety and cortisol levels in children with CD was also found by McBurnett et al. (1991). Thus, low HPAaxis activity seems to indicate fearlessness and thus hyporesponsivity to threatening stimuli (Van Goozen et al., 2000). Accordingly, a recent study showed that children with $\mathrm{CD}$ and high callousunemotional traits exhibit low cortisol reactivity compared to CD children with low levels of callous-unemotional traits (Stadler et al., 2010). A meta-analysis conducted by Hawes et al. (2009) supports the prediction that low levels of cortisol are associated with a risk for childhood antisocial behavior, but the relationship is not as strong as assumed. This lack of a strong association may be due to the fact that the relationship between HPA-axis activity and antisocial behavior varies depending on type of aggressive behavior, the presence or absence of callous-unemotional traits, patterns of internalizing comorbidity, and early environmental adversity.

In addition to specific aggression subtypes, one should also take into consideration that different hormones might interact and determine the etiology of aggression simultaneously. Popma et al. (2007) demonstrated that testosterone and aggression were only positively correlated in delinquent boys with low basal cortisol levels whereas there was no relationship between testosterone and aggression in those with high basal cortisol levels. Similarly, Dabbs et al. (1991) found a stronger relationship between testosterone levels and violence in male adolescents with low cortisol levels, compared to those with high cortisol levels. These findings indicate that high cortisol levels might be protective against aggression. Thus, intact cortisol reactivity might buffer the effect of other risk factors by increasing anxiety levels or behavioral inhibition (Kagan et al., 1988).

Moreover, Van de Wiel et al. (2004) demonstrated that disruptive children who exhibit low cortisol reactivity profit less from an intervention aimed at decreasing behavioral problems compared to children with intact cortisol reactivity. The knowledge that children with low cortisol reactivity might be at risk for developing aggressive behavior and might be resistant to current intervention programs leads to the necessity to develop new treatment approaches. Patients with an elevated biological risk should perhaps be treated with psychopharmacological means or additive methods aimed at adjusting the biological alterations, before or in combination with psychotherapeutic procedures.

Although several studies demonstrated a positive relationship between testosterone and DBDs (Scerbo and Kolko, 1994; Brooks and Reddon, 1996, Gerra et al., 1998), the correlation between aggression and testosterone in humans is less clear-cut than in animals (Archer, 1991; Archer et al., 2005). Some studies failed to find abnormal testosterone levels in children with CD (Van Goozen et al., 1998b; Loney et al., 2006) or in association with callous-unemotional traits (Loney et al., 2006). Van Goozen et al. (1998a) found that adrenal androgens were significantly higher in boys with CD than normal controls and other psychiatric controls (Van Goozen et al., 2000) and were strongly associated with aggression and delinquency (Van Goozen et al., 1998b). In a prospective longitudinal study, disruptive boys had higher levels of the main androgen metabolites testosterone and 5alpha-dihydrotestosterone (Maras et al., 2003).The relationship between testosterone and aggressive behavior seems to be gender-specific and modulated to some extent by comorbid symptoms such as attention problems (Granger et al., 2003). Furthermore, recent findings indicate that testosterone levels are related to social dominance, (Mazur and Booth, 1998; Rowe et al., 2004; Van Bokhoven et al., 2006) or peer-group leadership (Rowe et al., 2004) rather than aggression per se. One further explanation why studies have yielded mixed results (for an overview see also Van Goozen and Fairchild, 2009) may be that the relationship between testosterone and aggression is modulated by genetic factors. Recently, Sjöberg et al. (2008) demonstrated that testosterone levels and monoamine oxidase A (MAOA) genotype interact to predict antisocial behavior. Relative to controls, testosterone levels were elevated only in those patients with antisocial personality disorder expressing the low-activity form of the MAOA.

Although the impact of testosterone on aggressive behavior still is not fully clarified, interestingly, there is evidence indicating that testosterone modulates the processing of emotional stimuli: In humans and non-human animals, testosterone reduces central fear responses and stress axis reactivity (Van Honk et al., 2005; Hermans et al., 2006, 2007) as well as the aversive responses to unconscious threat stimuli (Wirth and Schultheis, 2007). This lack of perceived threat may make high-testosterone individuals more likely to engage in testosterone-facilitated dominance behavior, and to approach dominance challenges, thus leading to an impaired detection of social signals that serve the correction of behavior and the inhibition of aggression.

\section{GENETIC FACTORS}

Twin, adoption, and family studies suggest genetic influences on aggression (Miles and Carey, 1997; Rhee and Waldman, 2002), with heritability estimates for dimensional measures of aggression ranging from $44 \%$ to $72 \%$ in adults. A consideration of specific behavioral or emotion processing components seems to be an effective approach in genetic research: The Twins Early Development Study (TEDS) has shown a remarkably high heritability for callous-unemotional traits (Viding et al., 2005). It is striking that high levels of antisocial behaviors combined with high levels of CU are under strong genetic influence and no influence of shared environment whereas antisocial behavior in children with low levels of CU shows moderate genetic and shared environmental influence.

In addition, behavioral genetic studies have provided evidence that heritable factors are important for both subtypes of aggressive behavior, proactive and reactive aggression (Brendgen et al., 2006; Baker et al., 2008). Whereas proactive aggression seems to be predominantly influenced by genetic variables, in reactive aggression genetic as well as non-shared environmental influences seem to 
contribute to the course and the stability of aggression (Tuvblad et al., 2009). Proactive aggressive behavior may thus be related to stable and heritable psychopathic callous-unemotional personality characteristics, which to some extent explains the genetic stability observed in proactive aggression.

Interestingly, advanced approaches combining genetic and neuroimaging studies have yielded evidence that a specific genetic vulnerability might be related to deficient neural processing of emotional stimuli. Mechelli et al. (2009) recently showed that the valine 158 methionine polymorphism is associated with increased gray matter volume and heightened reactivity during emotion processing within the limbic system in children. As this study was conducted in healthy children, further research in DBD is needed. However, these results indicate that genetic factors affect brain function and might thus moderate the vulnerability to affective psychopathology in childhood.

Since CD is a heterogeneous disorder that becomes manifest in various behavioral dimensions and often co-occurs with other child behavioral disorders including comorbid ADHD and emotional disorders, it is likely that different neurotransmitter systems and the relative balance between them have varying degrees of influence over the behavioral phenotype. Variations in genes involved in these neurotransmitter systems are likely to mediate this delicate balance and have an effect on the function of these neurotransmitters in the brain.

In addition, it seems that the influence of genetic factors is moderated by environmental factors (Caspi et al., 2002; see also below): A functional polymorphism in the gene encoding the neurotransmitter-metabolizing enzyme MAOA was found to moderate the effect of maltreatment. Maltreated children with a genotype conferring low levels of MAOA expression were at high risk to develop antisocial problems whereas children with high levels of MAOA expression were not. These findings may partly explain why not all victims of maltreatment grow up to victimize others, and they provide epidemiological evidence that genotypes can moderate children's sensitivity to environmental insults.

In humans, length variation of the serotonin (5-HT) transporter (5-HTT) gene-linked polymorphic region (5-HTTLPR) that results in allelic variation in 5-HTT expression is associated with decreased serotonergic function and 5-HT-mediated psychopathology. This specific polymorphism in the serotonin transporter gene is associated with deficits in early behavioral functioning and serotonin metabolism, and extreme aggression among monkeys who experienced insecure early attachment relationships but not in monkeys who developed secure attachment relationships with their mothers during infancy (Suomi, 2005).

Additional animal studies have suggested that specific serotonin receptors may be involved in impulsive behaviors. Investigations with knockout mice that lack the 5-HT1B receptor show increased cocaine acquisition and alcohol intake, as well as hyperactivity and aggressive behavior (Brunner et al., 1999).

\section{EARLY HEALTH FACTORS, PSYCHOSOCIAL FACTORS AND GENE-ENVIRONMENT-INTERACTION}

Early health factors as well as several psychosocial risk factors increase the probability for CD. For example, birth complications may impair brain development and lead to a dysregulation in biological processes that can ultimately result in aggressive and antisocial behavior (Raine, 2002a,b). One important factor which is assumed to be associated with deficient brain development is maternal smoking during pregnancy. Prenatal nicotine disrupts the development of the noradrenergic neurotransmitter system (Levin et al., 1996) and interferes with neural development and autonomic functioning.

Besides health factors, psychosocial and parental factors have to be considered. A child's risk of developing CD is increased by parent psychopathology: Maternal depression, paternal alcoholism and/or criminality and antisocial behavior in either parent (Pfiffner et al., 2005; Kopp and Beauchaine, 2007) have been specifically linked to DBDs. Inconsistent parenting, higher levels of punishment with a concurrent reduction in reasoning and rewards, parents' negative perception of their child's adjustment, and reduced parental monitoring are additional determinants of DBDs and, most notably, seem to predict high probability of transition from ADHD to ODD and CD (Patterson et al., 2000). There is some evidence that variables presumed environmental in the first instance (e.g., parenting) may also reflect underlying genetic vulnerability within families. For example, at least part of the relationship between parenting and child behavior might reflect parental response to the child's genetically influenced temperament: Larsson et al. (2008) revealed an underlying bidirectional process involved in parental negativity and childhood antisocial behavior. On the one hand, negative parenting environmentally mediates the risk for child antisocial behavior; on the other hand, Larsson et al. (2008) also showed a strong impact of genetically influenced antisocial behavior on parenting.

Life stressors such as poverty, unemployment, low socioeconomic status, and affiliation to an ethnic minority (McCabe et al., 2001) are known to have an adverse effect on parenting and are therefore also related to the development of DBDs. In general, the impact of psychosocial factors seems to be more relevant for disruptive behavior starting early in child development (McCabe et al., 2001). Loeber et al. (2005) showed that the proportion of boys committing violent offences linearly increases as a function of the number of risk factors: The probability of future violence ranges from $3 \%$ in the absence of risk factors to $100 \%$ with nine or more risk factors. The 11 strongest predictors were the following: truancy, low school motivation, onset of severe aggressive conduct problems before age 10, cruelty to people, depressed mood, physical aggression, callous or unemotional behavior, low family socio-economic status, high parental stress, and bad neighborhood. Besides the above-mentioned risk factors, protective factors have to be considered as well: Fergusson and Lynskey (1996) revealed that adolescents seem to be more resilient to externalizing behavior despite high exposure to family adversity during childhood when they had higher IQ, lower novelty seeking and lower affiliations with delinquent peers, thus showing a combination of favorable intellectual ability, temperamental characteristics, and wider environmental factors.

As mentioned above, recent studies also indicate that the impact of psychosocial factors can be influenced by genetic variables. There is some evidence that inconsistent findings in regard to specific genetic variants can be explained by gene-gene or gene-environment interactions. A significant gene-gene interaction was recently confirmed by the Mannheim Study of Children at Risk (Hohmann 
et al., 2009), indicating that genes in the dopamine and serotonin systems are related to externalizing behavior and that both interact: Adolescents carrying two copies of the 5-HTTLPR short allele and the DRD4 7r variant scored highest on aggressive and/or delinquent behavior compared to other genotypes.

In addition, there is mounting evidence demonstrating the interaction between early risk factors like physical abuse and specific genetic variants, e.g., a functional polymorphism in the promoter region of the MAOA gene (Caspi et al., 2002; Foley et al., 2004; KimCohen et al., 2006). Inconsistent findings regarding the interaction of genetic and early environmental factors (Haberstick et al., 2005; Huizinga et al., 2006) could reflect effects from various sources: In a family study by Thapar et al. (2005) low birth weight and the val alleles of the COMT gene predicted antisocial disorder in children with ADHD. Earlier physical abuse and genetic effects were also found in twin studies in association with conduct problems (Boivin et al., 2005; Jaffee et al., 2005). In addition, maternal hostile-reactive behaviors seem related to genetic factors in the child (see Moffit, 2005)

Previous adoption studies show significant genetic influence on delinquent behavior. The highest rate of delinquent behavior was discovered in adopted children with delinquent biological and adoptive parents, and the second highest if only the biological parents but not the adopting caregivers were delinquent (Bohman, 1996). The effect of parental separation (of the adopting parents) and negative emotionality of biological parents (prior to adoption) on the children adopted in early infancy was studied in the Colorado Adoption Project (CAP): Children's externalizing behavior at school and in the family correlated significantly with the negative emotionality in the divorced families compared to the nondivorced (O'Connor et al., 2003). The Twins Early Development Study (TEDS, Trouton et al., 2002) on approximately 3700 twins illustrated a high genetic influence on aggressive behavior when associated with callousness-unemotionality while the impact of environmental factors was weak (Viding et al., 2005). Similar findings were obtained from another large twin sample (Larsson et al., 2006). Viding et al. (2009) furthermore revealed that, contrary to the development of callous-unemotional traits, negative parental discipline operates as a non-shared environmental risk factor for development of conduct problems during the transition to early adolescence.

Studying familial mechanisms, Deater-Deckard et al. (1999) separated genetic parental effects (warmth, acceptance negativity, hostility, withdrawal) from those stemming from the child (low task orientation). The latter contributed more to the genetic variance than familial factors. In later studies on the same group of children (Deater-Deckard and O'Connor, 2000; Deater-Deckard and Petrill, 2004) conduct problems covaried not only with parental negative affect and control as well as with some educational situations but also showed a genetic effect (higher concordance in MZ vs. DZ twins).

\section{TEMPERAMENTAL AND SOCIAL COGNITIVE RISK FACTORS}

It has been proposed that the ability to cognitively control behavior and emotions is determined by various temperament factors (Cloninger, 1987). Certain temperamental vulnerabilities can disrupt normal developmental processes during early childhood, such as the development of emotional regulatory abilities.
Temperamental factors can thus place a child at risk for antisocial and aggressive behavior (Robison et al., 2005). Recent evidence shows that reactive aggression in adolescence is predicted by temperamental difficulties in childhood (Vitaro and Brendgen, 2002; Ortitz and Gandara, 2006). More specifically, reactively aggressive preadolescents have shown more negative emotionality (e.g., irritability) during earlier childhood than proactively aggressive or non-aggressive peers (Vitaro and Brendgen, 2002). The risk for the development of aggressive behavior problems is also markedly increased in children and adolescents with high impulsivity/ novelty seeking (Tremblay et al., 1994; Schmeck and Poustka, 2001) and to some extent in adolescents with reduced anxiety or harm avoidance (Sigvardsson et al., 1987). Children with low anxiety are likely to respond less to punishment cues or may represent the subtype of conduct-disordered children with callous-unemotional traits (Christian et al., 1997), predicting an especially severe and chronic pattern of conduct problems and delinquency (Frick et al., 2005). As already mentioned, callous-unemotional traits are highly heritable (Viding et al., 2005, 2009) and are associated with low cortisol levels (Loney et al., 2006; Stadler et al., 2010) and abnormal fMRI responses to emotional stimuli (Marsh et al., 2008; Jones et al., 2009).

Cumulative and interacting effects of different risk factors have to be kept in mind. Children with a difficult temperament are, for example, at high risk to provoke negative parenting and, as a consequence, harsh parental discipline might negatively contribute to social cognitive processing in the child (Vitaro et al., 2006). Adequate social cognitive processes comprising the encoding of social stimuli, interpretation of cues, clarification of goals, access of adequate behavioral responses are affected in aggressive children. A number of studies have shown that reactively aggressive children misread interpersonal cues and interpreted ambiguous or prosocial communication as hostile, whereas proactive aggressive children mostly show problems concerning the clarification of goals, response access and response decision (Dodge and Coie, 1987; Crick and Dodge, 1996).

\section{TREATMENT}

Given the high prevalence and chronicity of DBDs, their effective treatment is a major public health challenge. Psychopharmacotherapeutic approaches for ODD and CD comprise neuroleptics and mood stabilizers and, in ADHD, mostly psychostimulants (for a review see Steiner et al., 2003). Whereas psychosocial treatment approaches theoretically might be effective for both proactive and reactive aggression, psychopharmacology appears effective in the first instance for reactive types of aggression as its effectiveness is mediated by a reduction of impulsivity which is mainly biologically determined (Steiner et al., 2003). Furthermore, psychopharmacological treatment is often limited by side-effects and is usually not effective beyond the treatment period. Nonpharmacologic approaches therefore play an important role in the treatment of DBD.

In general, cognitive-behavioral therapy has been used to alter highly reactive-aggressive behavior. Psychotherapeutic interventions focus on anger management, hostile attribution biases and problem-solving skills. On the other hand, highly proactive aggressive behavior could be influenced by contingency management 
procedures and social problem-solving skills programs that focus on making aggressive children identify and perceive the negative effect of their aggressive and antisocial behavior. However, accumulating evidence indicates that that the proactive subtype is less treatment sensitive (Vitiello and Stoff, 1997). This might be due to the biologically determined hyporesponsiveness to punishment cues that interferes with contingency management therapy, e. g. the application of negative consequences to aggression.

According to Kazdin $(1997,2000)$ three treatment approaches have been well evaluated in the past and show significant evidence: Parent management therapy (PMT), cognitive problem-solving skills training (PSST) and multi-systemic therapy (MST). Parent management therapy commonly uses interventions focused on parenting factors, like coercive social interactions between child and parents or teachers. Major components of parent training programs include: contingency management; increasing parents' ability to monitor and respond appropriately to the child's behavior; clear and concrete and specific goal/target setting; and application of rewards and of appropriate negative consequences. Parent training also focuses on the reduction of parental stress and burden since the interaction between psychosocial adversity and child risk factors further advance the development to severe DBDs.

Whereas cycles of early coercive behaviors in childhood between parent (and teacher) and child are clearly one of the earliest and most powerful antecedents of antisocial behavior, other dysfunctional domains like peer settings become more and more powerful in middle childhood. Children who are oppositional and aggressive toward their parents are at high risk to become involved in aggressive, rejecting relationships with peers. Such relationships accelerate the further development of antisocial behavior (Reid et al., 1999) even beyond specific individual deficits in disruptive children (i.e., poor emotional control and problem-solving skills), and also aggravate internalizing symptoms (e.g., poor self-esteem, depression). As the efficacy of PMT programs declines with increasing age (Barkley, 1997), psychotherapeutic interventions that focus on cognitive processes (e.g., problem-solving skills) are being increasingly applied in middle childhood and adolescence.

This has lead to the development of multi-focused psychosocial programs for child conduct problems (Kazdin et al., 1987; WebsterStratton et al., 2004). These programs emphasize social skills, problem-solving techniques, and anger management strategies in reducing child aggression and conduct problems, and individual therapy approaches based on the principals of cognitive-behavioral therapy (Durlak et al., 1991).

Multi-focused psychosocial interventions given early in life to at-risk children have most consistently been shown to be effective and sustainable (Webster-Stratton and Taylor, 2001; Farmer et al., 2002; Kazdin, 2006). However, treatments for youngsters with already well-established disorders of aggression are neither robust nor well-established (Connor et al., 2006).

Multi-Systemic Treatment (MST) is an effective intervention that has been developed to treat severely aggressive adolescents with chronic juvenile justice histories (Henggeler and Borduin, 1990; Henggeler et al., 1993; Chamberlain and Reid, 1998; Borduin, 1999). MST focuses on the individual, family, and extra-familial systems and their interrelations as a way to reduce symptoms and to promote prosocial behavior.
It should be noted that there are limitations to the extant treatment programs. Several biological and psychosocial risk factors might influence treatment outcome. Moreover, parental psychopathology may diminish the effectiveness of PMT and family interventions (Beauchaine et al., 2005). Family structures characterized by single parents, younger mothers, homes headed by a non-biological parent or contact with antisocial peers or low child cognitive functions are further adversarial moderators (Connor et al., 2006).

Concerning biological factors, it was shown that autonomically hypo-aroused children might benefit less from a multi-focused intervention program comprising PMT and PSST in a day-care setting (Stadler et al., 2008). In addition, Van de Wiel et al. (2004) showed that disruptive children who are less responsive to stress in terms of cortisol reactivity benefit less from an intervention aimed at decreasing behavioral problems. Thus, for selecting the best possible treatment options, further continued research is needed to examine biological and psychosocial predictors of treatment outcome.

In summary, it can be concluded that parent management training, cognitive-behavioral approaches, problem-solving skill training and multi-systemic approaches are more effective than individual or group psychodynamic or traditional unfocused and open-ended psychotherapy approaches (Kazdin, 1997; Connor et al., 2006). With regard to the high comorbidity with other externalizing and internalizing disorders as well with learning disabilities and associated academic failure, successful intervention also has to focus on comorbid symptoms. Thus, intervention must be multidisciplinary, usually requiring several components of medical, mental health, case management, and educational intervention (Steiner and Dunne, 1997).

\section{DISCUSSION AND PERSPECTIVES}

A growing body of data indicates that there are neurobiological factors that increase the risk for developing DBDs. It was already outlined that this does not imply an absence of environmental impact (Hinshaw and Lee, 2003; Rutter, 2005). Neuroscience research has to consider the interacting influence of biological and social risk factors, e.g., maltreatment or parental factors. Social factors might increase the risk for the development of CD, but on the other hand there is compelling evidence that protective social factors can counteract a biologically determined vulnerability. As already mentioned, in monkeys a specific polymorphism in the serotonin transporter gene is associated with deficits in early neurobehavioral functioning, serotonin metabolism and aggression only in those monkeys who experienced insecure early attachment relationships but not in monkeys with secure attachment (Suomi, 2005).

Thus, conflicting results from studies in children with disruptive behavior might be due to insufficient consideration of interacting psychosocial factors. Moreover, inconsistencies in the literature are due to the symptom heterogeneity of DBDs and the diversity of behavioral constructs. In addition, contradictory results in neuroscience might also originate from methodological problems like the diversity of studied groups including symptom heterogeneity as well as age differences (Lorber, 2004). A promising approach in investigating biological mechanisms might be the use of experimen- 
tal methods for assessing specific types of aggressive behavior. For example, lower affinity of 5-HT uptake in conduct-disordered boys was revealed only in those boys who showed high anger reactivity to an experimentally induced provocation (Stadler et al., 2004). Thus, subclassifications at the symptom level, such as proactive versus reactive aggression, seem to be more helpful in studying underlying biological and neuropsychological mechanisms of DBDs than the use of the diagnostic criteria provided by DSM-IV or ICD-10. Assuming, for example, that serotonergic dysfunction is associated more closely with specific basic psychopathological dimensions like impulsive reactive aggression, it may be beneficial to use methods that assess this particular phenotype and thus distinguish this type from other forms of aggressive behavior which may not be associated with biological markers. Problems associated with the heterogeneity of patient samples could be overcome by using assessment tools that yield - over and above medical taxonomy - empirically derived data specifying the diagnosis CD. Several questionnaires have been developed in order to assess proactive and reactive aggression in children (for a review see Kempes et al., 2005).

\section{REFERENCES}

American Psychiatric Association. (1994). Diagnostic and statistical manual of mental disorders. DSM-IV, 4th Edn. Washington DC:American Psychiatric Association.

Anderson, S. W., Bechara, A., Damasio, H., Tranel, D., and Damasio, A. R. (1999). Impairment of social and moral behavior related to early damage in human prefrontal cortex. Nat. Neurosci. 2, 1032-1037.

Archer, J. (1991). The influence of testosterone on human aggression. $\mathrm{Br}$. J. Psychol. 82, 1-28.

Archer, J., Graham-Devan, N., and Davies, M. (2005). Testosterone and aggression: a reanalysis of Book, Starzyk, and Quinsey's (2001) study. Aggress. Violent Behav. 10, 241-261.

Baker, L. A., Raine, A., Liu, J., and Jacobson, K. C. (2008). Differential genetic and environmental influences on reactive and proactive aggression in children. J. Abnorm. Child Psychol. 36, 1265-1278.

Baker, L. A., Tuvblad, C., Reynolds, C., Zheng, M., Lozano, D. I., and Raine, A. (2009). Resting heart rate and the development of antisocial behaviour from age 9 to 14: genetic and environmental influences. Dev. Psychopathol. 21, 939-960.

Barkley, R. A. (1997). Defiant Children: A Clinician's Manual for Assessment and Parent Training, 2nd Edn. New York, NY: Guilford Press.

Barry, T. D., Thompson, A., Barry, C. T., Lochman, J. E., Adler, K., and Hill, K. (2007). The importance of narcissism in predicting proactive and reactive aggression in moderately to highly aggressive children. Aggress. Behav. 33, 185-197.
Beauchaine, T. P., Webster-Stratton, C., and Reid, M. J. (2005). Mediators, moderators and predictors of 1-year outcomes among children treated for early-onset conduct problems: a latent growth curve analysis. J. Consult. Clin. Psychol. 73, 371-388.

Blair, R. J. (2001). Neuro-cognitive models of aggression, the antisocial personality disorders and psychopathy. J. Neurol. Neurosurg. Psychiatr. 71, 727-731.

Blair, R. J. (2003). Neurobiological basis of psychopathy. Br. J. Psychiatry 182, 5-7.

Blair, R. J. (2005). Responding to the emotions of others: dissociating forms of empathy through the study of typical and psychiatric populations. Conscious. Cogn. 14, 698-718.

Blair, R. J. (2006). The emergence of psychopathy: implications for the neuropsychological approach to developmental disorders. Cognition 101, 414-442.

Blair, R. J., Colledge, E., Murray, L., and Mitchell, D. G. (2001). A selective impairment in the processing of sad and fearful expressions in children with psychopathic tendencies. J. Abnorm. Child Psychol. 29, 491-498.

Bohman, M. (1996). Predisposition to criminality: Swedish adoption studies in retrospect. Ciba Found. Symp. 194, 99-109; discussion, 109-114.

Boivin, M., Perusse, D., Dionne, G., Saysset, V., Zoccolillo, M., Tarabulsy, G. M., Trembley, N., and Trembley, R. E. (2005). The genetic-environmental etiology of parents' perceptions and self-assessed behaviours toward their 5-month-old infants in a large twin and singleton sample. J. Child. Psychol. Psychiatry 46, 612-630.

Although our knowledge on neurobiological correlates of disruptive behavior considerably increased in the last years, neurobiological correlates can only be applied at the group level and are far from being specific enough to be used as a diagnostic or screening tool in individuals. Second, due to the immense plasticity of the nervous system, longitudinal studies of neurobiological markers, optimally starting at birth, would greatly help to understand their contribution to long-term behavioral outcome. Importantly, children with an elevated biological risk should not be judged as not capable of change or impervious to intervention or prevention methods. Concerning the application of psychotherapeutic interventions, the most effective method appears to be an integrated approach that considers both the child and the family, within a variety of contexts throughout the developmental stages of the child and family's life. Due to the heterogeneity of DBDs, future research should focus on the investigation of biological and psychosocial correlates of specific subtypes of aggressive behavior with possibly different etiology and specific treatment needs.

Borduin, C. M. (1999). Multisystemic treatment of criminality and violence in adolescents. J. Am. Acad. Child Adolesc. Psychiatry 38, 242-249.

Brendgen, M., Vitaro, F., Boivin, M., Dioone, G., and Perusse, D. (2006). Examining genetic and environmental effects on reactive versus proactive aggression. Dev. Psychol. 42, 1299-1312.

Brendgen, M., Vitaro, R., Tremblay, R. E., and Lavoie, F. (2001). Reactive and proactive aggression: predictions to physical violence in different contexts and moderating effects of parental monitoring and caregiving behavior. J. Abnorm. Child. Psychol. 29, 293-304.

Brooks, J. H., and Reddon, J. R. (1996) Serum testosterone in violent and nonviolent young offenders. J. Clin. Psychol. 52, 475-483.

Brunner, D., Buhot, M. C., Hen, R., and Hofer, M. (1999). Anxiety, motor activation, and maternal-infant interactions in 5HT1B knockout mice. Behav. Neurosci. 113, 587-601.

Bushman, B. J., and Anderson, C. A. (2001). Is it time to pull the plug on hostile versus instrumental aggression dichotomy? Psychol. Rev. 108, 273-279.

Carr, M. B., and Lutjemeier, J. A. (2005). The relation of facial affect recognition and empathy to delinquency in youth offenders. Adolescence 40, 601-619.

Caspi, A., McClay, J., Moffitt, T. E., Mill, J., Martin, J., Craig, I. W., Taylor, A., and Poulton, R. (2002). Role of genotype in the cycle of violence in maltreated children. Science 297, 851-854.

Castellanos, F. X., Elia, J., Kruesi, M. J., Gulotta, C. S., Mefford, I. N., Potter, W. Z., Ritchie, G. F., and Rapoport,
J. L. (1994). Cerebrospinal fluid monoamine metabolites in boys with attention-deficit-hyperactivity disorder. Psychiatry Res. 52, 306-316.

Chamberlain, P., and Reid, J. B. (1998). Comparison of two community alternatives to incarceration for chronic juvenile offenders. J. Consult. Clin. Psychol. 66, 624-633.

Christian, R. E., Frick, P. J., Hill, N. L., Tyler, L., and Frazer, D. R. (1997). Psychopathy and conduct problems in children: II. Implications for subtyping children with conduct problems. J. Am. Acad. Child Adolesc. Psychiatry. 36, 233-241.

Clarke, R. A., Murphy, D. L., and Constantino, J. N. (1999). Serotonin and externalizing behavior in young children. Psychiatry Res. 86, 29-40.

Cloninger, C. R. (1987). A systematic method for clinical description and classification of personality. Arch. Gen. Psychiatry 44, 573-588.

Connor, D. F., Carlson, G.A., Chang, K. D., Daniolos, P. T., Ferziger, R., Findling, R. L., Hutchinson, J. G., Malone, R. P., Halperin, J. M., Plattner, B., Post, R. M., Reynolds, D. L., Rogers, K. M., Saxena, K., Steiner, H., and Stanford/Howard/ AACAP Workgroup on Juvenile Impulsivity, and Aggression. (2006). Juvenile maladaptive aggression: a review of prevention, treatment, and service configuration and a proposed research agenda. J. Clin. Psychiatry 67, 808-820.

Constantino, J. N., and Murphy, D. L. (1996). Monoamine metabolites in 'leftover' newborn human cerebrospinal fluid - a potential resource for biobehavioral research. Psychiatry Res 65, 129-142.

Cook, E. H. Jr., Stein, M. A., Ellison, T., Unis, A. S., and Leventhal, B. L. (1995). 
Attention deficit hyperactivity disorder and whole-blood serotonin levels: effects of comorbidity. Psychiatry Res. 57, 13-20.

Crick, N. R., and Dodge, K. A. (1996). Social information-processing mechanisms on reactive and proactive aggression. Child Dev. 67, 993-1002.

Dabbs, J. M., Jurkovic, G. J., and Frady, R. L. (1991). Salivary testosterone and cortisol among late adolescent male offeneders. J. Abnorm. Child Psychol. 19, 496-478.

Davidson, R. J., Putnam, K. M., and Larson, C. L. (2000). Dysfunction in the neural circuitry of emotion regulation - a possible prelude to violence. Science 289, 591-604.

De Brito, S. A., Mechelli, A., Wilke, M., Laurens, K. R., Jones, A. P., Barker, G. J., Hodgins, S., and Viding, E. (2009). Size matters: increased grey matter in boys with conduct problems and callous-unemotional traits. Brain 132, 843-852.

De Vignemont, F., and Singer, T. (2006). The empathic brain: how, when and why? Trends Cogn. Sci. 10, 435-441.

Deater-Deckard, K., Fulker, D. W., and Plomin, R. (1999). A genetic study of the family environment in the transition to early adolescence. J. Child. Psychol. Psychiatry 40, 769-775.

Deater-Deckard, K., and O'Connor, T. G. (2000). Parent-child mutuality in early childhood: two behavioral genetic studies. Dev. Psychol. 36, 561-570.

Deater-Deckard, K., and Petrill, S. A. (2004). Parent-child dyadic mutuality and child behavior problems: an investigation of gene-environment processes. J. Child. Psychol. Psychiatry 45, 1171-1179.

DeRijk, R. H., Wüst, S., Meijer, O. C., Zennaro, M. C., Federenko, I. S., Hellhammer, D. H., Giacchetti, G., Vreugdenhil, E., Zitman, F. G., and de Kloet, E. R. (2006). A common polymorphism in the mineralocorticoid receptor modulates stress responsiveness. J. Clin. Endocrinol. Metab. 91, 5083-5089.

Dodge, K. A., and Coie, J. D. (1987). "Social-information processing factors in reactive and proactive aggression," in The Development and Treatment of Childhood Aggression, eds D. J. Pepler and K. H. Rubin (Hillsdale, NJ: Erlbaum), 201-218.

Dodge, K. A., and Schwartz, D. (1997). "Social information-processing mechanisms in aggressive behaviour," in Handbook of Antisocial Behaviour, eds D. M. Stoff, J. Breiling, and J. D. Maser (New York: Wiley), 171-180.

Dolan, R. J. (2002). Emotion, cognition, and behavior. Science 298, 1191-1194.
Durlak, J.A., Fuhrman, T., and Lampman, C. (1991). Effectiveness of cognitivebehavior therapy for maladapting children: a meta-analysis. Psychol. Bull. 110, 204-214.

Fairchild, S., von Goozen, S., Stollery, J., Brown, J., Gardiner, J., Herbert, J., and Goodyer, I. M. (2008). Cortisol diurnal rhythm and stress reactivity in male adolescents with early-onset or adolescence-onset conduct disorder. Biol. Psychiatry 64, 599-606

Farmer, E. M., Compton, S. C., Burns, B. J., and Robertsons, E. (2002). Review of the evidence base for treatment of childhood psychopathology: externalizing disorders. J. Consult. Clin. Psychol. 70, 1267-1302.

Fergusson, D. M., and Lynskey, M. T. (1996). Adolescent resiliency to family adversity. J. Child. Psychol. Psychiatry 37, 281-292.

Foley, D. L., Eaves, L. J., Wormley, B., Silberg, J. L., Maes, H.H., Kuhn, J., and Riley, B. (2004). Childhood adversity, monoamine oxidase a genotype, and risk for conduct disorder. Arch. Gen. Psychiatry 61, 738-744.

Frick, P. J., Stickle, T. R., Dandreaux, D. M., Farrell, J. M., and Kimonis, E. R. (2005). Callous-unemotional traits in predicting the severity and stability of conduct problems and delinquency. $J$. Abnorm. Child Psychol. 33, 471-487.

Frick, P. J., and White, S. F. (2008). Research review: the importance of callous-unemotional traits for developmental models of aggressive and antisocial behavior. J. Child. Psychol. Psychiatry 49, 359-375.

Gao, Y., Raine, A., Venables, P.H., Dawson, M. E., and Mednick, S. A. (2010). Association of poor childhood fear conditioning and adult crime. Am. J. Psychiatry 167, 56-60.

Gerra, G., Zaimovic, A., Giucastro, G., Folli, F., Maestri, D., Tessoni, A., Avanzini, P., Caccavari, R., Bernasconi, S., and Brambilla, F. (1998). Neurotransmitter-hormonal responses to psychological stress in peripubertal subjects: relationship to aggressive behavior. Life Sci. 62, 617-625.

Gordis, E. B., Granger, D. A., Susman, E. J., and Trickett, P. K. (2006). Asymmetry between salivary cortisol and alphaamylase reactivity to stress: relation to aggressive behavior in adolescents. Psychoneuroendocrinology 31, 976-987.

Granger, D. A., Shirtcliff, E. A., ZahnWaxler, C., Usher, B., Klimes-Dougan, B., and Hastings, P. (2003). Salivary testosterone diurnal variation and psychopathology in adolescent males and females: individual differences and developmental effects. Dev. Psychopathol. 15, 431-449.
Haberstick, B. C., Lessem, J. M., Hopfer, C. J., Smolen, A., Ehringer. M. A., Timberlake, D., and Hewitt, J. K. (2005). Monoamine oxidase A (MAOA) and antisocial behaviors in the presence of childhood and adolescent maltreatment. Am. J. Med. Genet. B Neuropsychiatr. Genet. 135, 59-64.

Halperin, J. M., Newcorn, J. H., Schwartz, S. T., Sharma, V., Siever, L. J., Koda, V. H., and Gabriel, S. (1997). Age-related changes in the association between serotonergic function and aggression in boys with ADHD. Biol. Psychiatry $41,682-689$.

Halperin, J. M., Sharma, V., Siever, L. J., Schwartz, S. T., Matier, K., Wornell, G., and Newcorn, J. H. (1994). Serotonergic function in aggressive and nonaggressive boys with attention deficit hyperactivity disorder. Am. J. Psychiatry 151, 243-248.

Hanna, G. L., Yuwiler, A., and Coates, J. K. (1995). Whole blood serotonin and disruptive behaviors in juvenile obsessive-compulsive disorder. J. Am. Acad. Child Adolesc. Psychiatry 34, 28-35.

Hawes, D. J., Brennan, J., and Dadds, M. R. (2009). Cortisol, callous-unemotional traits, and pathways to antisocial behavior. Curr. Opin. Psychiatry 22, 357-362.

Henggeler, S. W., and Borduin, C. M. (1990). Family Therapy and Beyond; A Multisystemic Approach to Treating the Behavior Problems of Children and Adolescents.Pacific Grove, CA: Brooks/ Cole.

Henggeler, S. W., Melton, G. B., Smith, L. A., Schoenwald, S. K., and Hanley, J. H. (1993). Family preservation using multisystemic treatment: long-term follow-up to a clinical trial with serious juvenile offenders. J. Child Fam. Stud. 4, 283-293.

Hermans, E. J., Putman, P., Baas, J. M., Gecks, N. M., Kenemans, J. L., and van Honk, J. (2007). Exogenous testosterone attenuates the integrated central stress response in healthy young women. Psychoneuroendocrinology 32 , 1052-1061.

Hermans, E. J., Putman, P., Baas, J. M., Koppeschaar, H. P., and van Honk, J. (2006). A single administration of testosterone reduces fear-potentiated startle in humans. Biol. Psychiatry 59, 872-874.

Herpertz, S. C., Huebner, T., Marx, I., Vloet, T. D., Fink, G. R., Stoecker, T., Shah, N. J., Konrad, K., and HerpertzDahlmann, B. (2008). Emotional processing in male adolescents with childhood-onset conduct disorder. J. Child Psychol. Psychiatry 49, 781-791.

Herpertz, S. C., Mueller, B., Qunaibi, B., Lichterfeld, C., Konrad, K., and Herpertz-Dahlmann, B. (2005). Response to emotional stimuli in boys with conduct disorder. Am. J. Psychiatry 162, 1100-1107.

Herpertz, S. C., Mueller, B., Wenning, B., Qunaibi, M., Lichterfeld, C., and Herpertz-Dahlmann, B. (2003). Autonomic responses in boys with externalizing disorders. J. Neural Transm. 110, 1181-1195.

Herpertz, S. C., Wenning, B., Müller, B., Qunaibi, M., Sass, H., and Herpertz-Dahlmann, B. (2001). Psychophysiological responses in ADHD boys with and without conduct disorder: implications for adult antisocial behavior. J. Am. Acad. Child Adolesc. Psychiatry 40, 1222-1230.

Hinshaw, S. P., and Lee, S. S. (2003). Oppositional Defiant and Conduct Disorder, in Child Psychopathology by E. J. Mash, R. J. Barkley. New York: Guilford Press, 144-198.

Hohmann, S., Becker, K., Fellinger, J., Banaschewski, T., Schmidt, M. H., Esser, G., and Laucht, M. (2009). Evidence for epistasis between the 5-HTTLPR and the dopamine D4 receptor polymorphisms in externalizing behavior among 15 -year-olds. J. Neural Transm. 116, 1621-1629.

Huebner, T., Vloet, T. D., Marx, I., Konrad, K., Fink, G. R., Herpertz, S. C., and Herpertz-Dahlmann, B. (2008). Morphometric brain abnormalities in boys with conduct disorder. J. Am. Acad. Child Adolesc. Psychiatry 47, 540-547.

Hughes, C. W., Petty, F., Shiekha, S., and Kramer, G. L. (1996). Whole-blood serotonin in children and adolescents with mood and behavior disorders. Psychiatry Res. 65, 79-95.

Huizinga, D., Haberstick, B. C., Smolen, A., Menard, S., Young, S. E., Corley, R. P., Stallings, M. C., Grotpeter, J., and Hewitt, J. K. (2006). Childhood maltreatment, subsequent antisocial behavior, and the role of monoamine oxidase A genotype. Biol. Psychiatry 60, 677-683.

Jaffee, S. R., Caspi, A., Moffitt, T.E., Dodge, K. A., Rutter, M., Taylor, A., and Tully, L.A. (2005). Nature $\times$ nurture: genetic vulnerabilities interact with physical maltreatment to promote conduct problems. Dev. Psychopathol. 17, 67-84.

Jones, A. P., Laurens, K. R., Herba, C. M., Barker, G. J., and Viding, E. (2009). Amygdala hypoactivity to fearful faces in boys with conduct problems and callous-unemotional traits. Am. J. Psychiatry 166, 95-102.

Kagan, J., Reznick, F. S., and Snidman, N. (1988). Biological bases of childhood shyness. Science 240, 167-171.

Kazdin, A. E. (1997). Practitioner review: psychosocial treatments for conduct disorder in children. J. Child. Psychol. Psychiatry 38, 161-178. 
Kazdin, A. E. (2000). Treatments for aggressive and antisocial children. Child Adolesc. Psychiatr. Clin. N. Am. 9, 841-858.

Kazdin, A. E. (2006). Multisystemic therapy reduces long term rearrest compared with usual treatment. J. Consult. Clin. Psychol. 73, 445-453.

Kazdin, A. E., Esveldt-Dawson, K., French, N. H., and Unis, A. S. (1987). Effects of parent management training and problem-solving skills training combined in the treatment of antisocial child behavior. J. Am. Acad. Child Adolesc. Psychiatry 26, 416-424.

Kempes, M., Matthys, W., de Vries, H., and van Engeland, H. (2005). Reactive and proactive aggression in children. A review of theory, findings and the relevance for child and adolescent psychiatry. Eur. Child Adolesc. Psychiatry 14, 11-19.

Kiehl, K. A., Smith, A. M., Hare, R. D., Mendrek, A., Forster, B. B., Brink, J., and Liddle, P. F. (2001). Limbic abnormalities in affective processing by criminal psychopaths as revealed by functional magnetic resonance imaging. Biol. Psychiatry 50, 677-684.

Kim-Cohen, J., Caspi, A., Taylor, A., Williams, B., Newcombe, R., Craig, I. W., and Moffitt, T. E. (2006). MAOA, maltreatment, and gene-environment interaction predicting children's mental health: new evidence and a metaanalysis. Mol. Psychiatry 11, 903-913.

Kopp, L. P., and Beauchaine, T. P. (2007). Patterns of psychopathology in the families of children with conduct problems, depression, and both psychiatric conditions. J. Abnorm. Child. Psychol. 35, 301-312.

Krueger, R. F., Hicks, B. M., Patrick, C. J., Carlson, S. R., Iacono, W. G., and McGue, M. (2002). Etiologic connections among substance dependence, antisocial behavior, and personality: modeling the externalizing spectrum. J. Abnorm. Psychol. 111, 411-424.

Kruesi, M. J., Casanova, M. F., Mannheim, G., and Johnson-Bilder, A. (2004). Reduced temporal lobe volume in early onset conduct-disorder. Psychiatry Res $132,1-11$.

Kruesi, M. J., Hibbs, E. D., Zahn, T. P., Keysor, C. S., Hamburger, S. D., Bartko, J. J., and Rapoport, J. L. (1992). A 2-year prospective follow-up study of children and adolescents with disruptive behavior disorders. Arch. Gen. Psychiatry 49, 429-435.

Kruesi, M. J., Rapoport, J. L., and Hamburger, S. (1990). Cerebrospinal fluid monoamine metabolites, aggression and impulsivity in disruptive behavior disorders of children and adolescents. Arch. Gen. Psychiatry 47, 419-426.
Lahey, B. B., Goodman, S. H., Waldman, I. D., Bird, H., Canino, G., Jensen, P., Regier, D., Leaf, P. J., Gordon, R., and Applegate, B. (1999). Relation of age of onset to the type and severity of child and adolescent conduct problems. J. Abnorm. Child. Psychol. 27, 247-260.

Lamarche, V., Brendgen, M., Boivin, M., Vitaro, F., Dionne, G., and Pérusse, D. (2007). Do friends' characteristics moderate the prospective links between peer victimization and reactive and proactive aggression? J. Abnorm. Child Psychol. 35, 665-680.

Larsson, H., Andershed, H., and Lichtenstein, P. (2006). A genetic factor explains most of the variation in the psychopathic personality. J. Abnorm. Psychol. 115, 221-230.

Larsson, H., Viding, E., Rijsdijk, F. V., and Plomin, R. (2008). Relationships between parental negativity and childhood antisocial behavior over time: a bidirectional effects model in a longitudinal genetically informative design. J. Abnorm. Child Psychol. 36, 633-645.

Le Marquand, D. G., Pihl, R. O., Young, S. N., Tremblay, R. E., Séguin, J. R., Palmour, R. M., and Benkelfat, C. (1998). Tryptophan depletion, executive functions, and disinhibition in aggressive, adolescent males. Neuropsychopharmacology 19 , 333-341.

Levin, E. D., Wilkerson, A., Jones, J. P., Christopher, N. C., and Briggs, S. J. (1996). Prenatal nicotine effects on memory in rats: pharmacological and behavioral challenges. Brain Res. Dev. Brain Res. 97, 207-215.

Loeber, R., Burke, J. D., Lahey, B. B., Winters, A., and Zera, M. (2000). Oppositional defiant and conduct disorder: a review of the past 10 years, part I. J. Am. Acad. Child Adolesc. Psychiatry 39, 1468-1484.

Loeber, R., Pardini, D. A., Homish, D. L., Wei, E. H., Crawford, A. M., Farrington, D. P., Stouthamer-Loeber, M., Creemers, J., Koehler, S. A., and Rosenfeld, R. (2005). The prediction of violence and homocide in young men. J. Consult. Clin. Psychol. 73, 1074-1088.

Loney, B. R., Butler, M. A., Lima, E. N., Counts, C. A., and Eckel, L. A. (2006). The relation between salivary cortisol, callous-unemotional traits, and conduct problems in an adolescent non-referred sample. J. Child. Psychol. Psychiatry 47, 30-36.

Loney, B. R., Frick, P. J., Clements, C. B., Ellis, M. L., and Kerlin, K. (2003). Callous-unemotional traits, impulsivity, and emotional processing in adolescents with antisocial behavior problems. J. Clin. Child. Adolesc. Psychol. 32, 66-80.
Lopez-Duran, N. L., Olson, S. L., Hajal, N. J., Felt, B. T., and Vazquez, D. M. (2009). Hypothalamic pituitary adrenal axis functioning in reactive and proactive aggression in children. J. Abnorm. Child. Psychol. 37, 169-182.

Lorber, M. F. (2004). Psychophysiology of aggression, psychopathy, and conduct problems: a meta-analysis. Psychol. Bull. 130, 531-552.

Maras, A., Laucht, M., Lewick, S., Haack, D., Malisova, L., and Scmidt, M. H. (2003). Bedeutung von Androgenen für externalisierende Verhaltensauffälligkeiten Jugendlicher. Z. Kinder Jugendpsychiatr. 31, 7-15.

Marsh, A. A., Finger, E. C., Mitchell, D. G., Reid, M. E., Sims, C., Kosson, D. S., Towbin, K. E., Leibenluft, E., Pine, D. S., and Blair, R. J. (2008). Reduced amygdala response to fearful expressions in children and adolescents with callous-unemotional traits and disruptive behavior disorders. Am. J. Psychiatry 165, 712-720.

Mazur, A., and Booth, A. (1998). Testosterone and dominance in men. Behav. Brain Sci. 21, 353-397.

McBurnett, K., Lahey, B. B., Frick, P. J. Risch, C., Loeber, R., Hart, E. L., Christ, M. A., and Hanson, K. S. (1991). Anxiety, inhibition, and conduct disorder in children: II. Relation to salivary cortisol. J. Am. Acad. Child Adolesc. Psychiatry 30, 192-196.

McBurnett, K., Lahey, B. B., Rathouz, P. J., and Loeber, R. (2000). Low salivary cortisol and persistent aggression in boys referred for disruptive behavior. Arch. Gen. Psychiatry 57, 38-43.

McCabe, K. M., Hough, R., Wood, P. A., and Yeh, M. (2001). Childhood and adolescent onset conduct disorder: a test of the developmental taxonomy. $J$. Abnorm. Child. Psychol. 29, 305-316.

Mechelli, A., Tognin, S., McGuire, P. K., Prata, D., Sartori, G., Fusar-Poli, P., De Brito, S., Hariri, A. R., and Viding, E. (2009). Genetic vulnerability to affective psychopathology in childhood: a combined voxel-based morphometry and functional magnetic resonance imaging study. Biol. Psychiatry 66, 231-237.

Miles, D. R., and Carey, G. (1997). Genetic and environmental architecture of human aggression. J. Pers. Soc. Psychol. 72, 207-217.

Moffitt, T. E. (2005). The new look of behavioral genetics in developmental psychopathology: gene-environment interplay in antisocial behaviors. Psychol. Bull. 131, 533-554.

Moffitt, T. E., Arseneault, L., Jaffee, S. R., Kim-Cohen, J., Koenen, K. C., Odgers, C. L., Slutske, W. S., and Viding, E. (2008). Research review: DSM-V conduct disorder: research needs for an evidence base. J. Child. Psychol. Psychiatry 49, 3-33.

Murray-Close, O., and Strov, J. M. (2009). A longitudinal study of forms and functions of aggressive behavor in early childhood. Child Dev. 80, 828-842.

O'Connor, T. G., Caspi, A., Defries, J. C., and Plomin, R. (2003). Genotypeenvironment interaction in children's adjustment to parental separation. J. Child. Psychol. Psychiatry 44, 849-856.

Ortitz, J., and Raine, A. (2004). Heart rate level and antisocial behavior in children and adolescents: a meta-analysis. J. Am. Acad. Child Adolesc. Psychiatry 43, 154-162.

Ortitz, M. A. C., and Gandara, V. d. B. (2006). Study on the relation between temperament, aggression, and anger in children. Aggress. Behav. 32, 207-215.

Pajer, K., Gardner, W., and Rubin, R. T. (2001). Decreased cortisol levels in adolescent girls with conduct disorder. Arch. Gen. Psychiatry 58, 297-302.

Patrick, C. J., and Bernat, E. M. (2009). "From markers to mechanisms: using psychophysiological measures to elucidate basic processes underlying aggressive externalizing behaviour," in The Neurobiological Basis of Violence: Science and Rehabilitation, eds S. Hodgins, E. Viding, and A. Plodowski, (New York: Oxford University Press), 202-223.

Patrick, C. J., Zempolich, K. A., and Levenston, G. K. (1997). "Emotionality and violent behaviour in psychopaths: a biosocial analysis," in Biosocial bases of Violence, eds A. Raine, P.A. Brennan, D. P. Farrington, and S. A. Mednick (New York: Plenum), (145-161).

Patterson, G. R., DeGarmo, D. S., and Knutson, N. (2000). Hyperactive and antisocial behaviors: comorbid or two points in the same process? Dev. Psychopathol. 12, 91-106.

Pfiffner, L. J., McBurnett, K., Rathouz, P. J., and Judice, S. (2005). Family correlates of oppositional and conduct disorders in children with attention deficit/ hyperactivity disorder. J. Abnorm. Child Psychol. 33, 551-563.

Pine, D. S., Coplan, J. D., Wasserman, G. A., Miller, L. S., Fried, J. E., Davies, M., Cooper, T. B., Greenhill, L., Shaffer, D., and Parsons, B. (1997). Neuroendocrine response to fenfluramine challenge in boys. Arch. Gen. Psychiatry 54, 839-846.

Pliszka, S. R., Rogeness, G. A., Renner, P. Sherman, J., and Broussard, T. (1988). Plasma neurochemistry in juvenile offenders. J. Am. Acad. Child Adolesc. Psychiatry 27, 588-594.

Plodowski, A., Gregory, S. L., and Blackwood, N. J. (2009). "Persistent violent offending among adult men: 
A critical review of neuroimaging studies," in The Neurobiological Basis of Violence: Science and Rehabilitation, eds S. Hodgins, E. Viding, and A. Plodowski (New York: Oxford University Press), 137-156.

Pompa, A. R., Jansen, L. M., Vermeiren, R., Steiner, H., Raine, A., Van Goozen, S. H., van Engeland, H., and Doreleijers, T.A.(2006). Hypothalamus-pituitaryadrenal axis and autonomic activity during stress in delinquent male adolescents. Psychoneuroendocrinology 31 , 948-957.

Pompa, A. R., Vermeiren, R., Geluk, C. A., Rinne, T., van den Brink, W., Knol, D. L., Jansen, L. M., van Engeland, H., and Doreleijers, T. A. (2007). Cortisol moderates the relationship between testosterone and aggression in delinquent male adolescents. Biol. Psychiatry 61, 405-411.

Raine, A. (1993). The Psychopathology of Crime. Criminal Behavior as a Clinical Disorder. New York: Academic Press.

Raine, A. (2002a). Annotation: the role of prefrontal deficits, low autonomic arousal, and early health factors in the development of antisocial and aggressive behavior in children. J. Child. Psychol. Psychiatry 43, 417-434.

Raine, A. (2002b). Biosocial studies of antisocial and violent behavior in children and adults: a review. J. Abnorm. Child Psychol. 30, 311-326.

Raine, A., Dodge, K., Loeber, R., GatzkeKopp, L., Lynam, D. R., Reynolds, C., Stouthamer-Loeber, M., and Liu, J. (2006). The Reactive-Proactive Aggression Questionnaire: differential correlates of reactive and proactive aggression in adolescent boys. Aggress. Behav. 32, 159-171.

Raine, A., Lencz, T., Bihrle, S., LaCasse, L., and Colletti, P. (2000). Reduced prefrontal graymatter volume and reduced autonomic activity in antisocial personality disorder. Arch. Gen. Psychiatry 57, 119-127.

Raine, A., Venables, P.H., and Williams, M. (1990). Relationships between central and autonomic measures of arousal at age 15 years and criminality at age 24 years. Arch. Gen. Psychiatry 47, 1003-1007.

Raine, A., Venables, P. H., and Williams, M. (1995). High autonomic arousal and electrodermal orienting at age 15 years as protective factors against criminal behavior at age 29 years. Am. J. Psychiatry 15, 1595-1600.

Raine, A., Venables, P., and Mednick, S. A. (1997). Interaction between birth complications and early maternal rejection in predisposing individuals to adult violence: specificity to serious, early-onset violence. Am. J. Psychiatry 154, 1265-1271.
Reid, B. J., Eddy, M. E., Fetrow, R. A., and Stoolmiller, M. (1999). Description and immediate impacts of a preventive intervention for conduct problems. Am. J. Community Psychol. 27, 483-517.

Rhee, S. H., and Waldman, I. D. (2002). Genetic and environmental influences on antisocial behavior: a meta-analysis of twin and adoption studies. Psychol. Bull. 128, 490-529.

Robison, S. D., Frick, P. J., and Sheffield, M. A. (2005). Temperament and parenting: implications for understanding developmental pathways to conduct disorder. Minerva Pediatr. 57, 373-388.

Rogeness, G.A., Hernandez,J.M., Macedo, C. A., and Mitchell. E. L. (1982). Biochemical differences in children with conduct disorder socialized and undersocialized.Am. J. Psychiatry 139, 307-311.

Rogers, M. A., Bellgrove, M. A., Chiu, E., Mileshkin, C., and Bradshaw, J. L. (2004a). Response selection deficits in melancholic but not non melancholic unipolar major depression. J. Clin. Exp. Neuropsychol. 26, 169-179.

Rogers, R. D., Lancaster, M., Wakeley, J., and Bhagwagar, Z. (2004b). Effects of beta-adrenoceptor blockade on components of human decisionmaking. Psychopharmacology (Berl.) 172, 157-164.

Rowe, R., Maughan, B., Worthman, C.M., Costello, E. J., and Angold, A. (2004). Testosterone, antisocial behavior, and social dominance in boys: pubertal development and biosocial interaction. Biol. Psychiatry 55, 546-552.

Rutter, M. (2005). Environmentally mediated risks for psychopathology: research strategies and findings. $J$. Am. Acad. Child Adolesc. Psychiatry 44, 3-18.

Salmivalli, C., and Helteenvuori, T. (2007). Reactive, but not proactive aggression predicts victimization among boys. Aggress. Behav. 33, 198-206.

Scerbo, A. S., and Kolko, D. L. (1994). Salivary testosterone and cortisol in disruptive children: relationship to aggressive, hyperactive, and internalizing behaviors. J. Am. Acad. Child Adolesc. Psychiatry 33, 1174-1184.

Schmeck, K., and Poustka, F. (2001). Temperament and disruptive behavior disorders. Psychopathology 34, 159-163.

Schulz, K. P., Newcorn, J. H., McKay, K. E., Himelstein, J., Koda, V. H., Siever, L. J., Sharma, V., and Halperin, J. M. (2001). Relationship between central serotonergic function and aggression in prepubertal boys: effect of age and attention-deficit/hyperactivity disorder. Psychiatry Res. 101, 1-10.
Sigvardsson, S., Bohman, M., and Cloninger, C. R. (1987). Structure and stability of childhood personality: prediction of later social adjustment. J. Child Psychol. Psychiatry 28, 929-946.

Sjöberg, R. L., Ducci, F., Barr, C. S., Timothy, K. N., Dell'Osso, L., and Virkkunen, M. Goldman, D. (2008). A non-additive interaction of functionalMAO-AVNTR and testosterone predicts antisocial behavior. Neuropsychopharmacology $33,425-430$.

Snoek, H., van Goozen, S. H., Matthys, W., Buitelaar, J. K., and van Engeland, H. (2004).Stress responsitivity in children with externalizing behavior disorders. Dev. Psychopathol. 16, 389-406.

Stadler, C., Grasmann, D., Fegert, J. M., Holtmann, M., Poustka, F., and Schmeck, K. (2008). Heart rate and treatment effect in children with disruptive behavior disorders. Child Psychiatry Hum. Dev. 39, 299-309.

Stadler, C. Kroeger, A.,Weyers, P., Grasmann, D., Horschinek, M., Freitag, C., and Clement, H.-W. (2010). Cortisol reactivity in boys with attention-deficit/ hyperactivity disorder and disruptive behavior problems: the impact of callous unemotional traits. Psychiatry Res. doi: 10.1016/j.psychres.2010.05.004. [Epub ahead of print].

Stadler, C., Schmeck, K., Nowraty, I., Müller, W. E., and Poustka, F. (2004). Platelet 5-HT uptake in boys with conduct disorder. Neuropsychobiology 50 , 244-251.

Stadler, C., Sterzer, P., Schmeck, K., Krebs, A., Kleinschmidt, A., and Poustka, F. (2006). Reduced anterior cingulate activity in aggressive children and adolescents during affective stimulation: the role of temperament traits. J. Psychiatr. Res. 41, 410-417.

Stadler, C., Zepf, F., Demisch, L., Schmitt, M., Landgraf, M., and Poustka, F. (2007). Influence of tryptophan depletion on laboratory-provoked aggression in ADHD. Neuropsychobiology $56,104-110$.

Steiner, H., and Dunne, J. E. (1997). Summary of the practice parameters for the assessment and treatment of children and adolescents with conduct disorder. J. Am. Acad. Child Adolesc. Psychiatry 36, 1482-1485.

Steiner, H., Saxena, K., and Chang, K. (2003). Psychopharmacologic strategies for the treatment of aggression in juveniles. CNS Spectr. 8, 298-308.

Sterzer, P., Stadler, C., Krebs, Kleinschmidt, A., and Poustka, F. (2005). Abnormal neural responses to emotional visual stimuli in adolescents with conduct disorder. Biol. Psychiatry 57, 7-15.

Sterzer, P., Stadler, C., Poustka, F., and Kleinschmidt, A. (2007). A structural neural deficit in adolescents with conduct disorder and its association with lack of empathy. Neuroimage 37, 335-342.

Suomi, S. J. (2005). Aggression and social behaviour in rhesus monkeys. Novartis Found. Symp. 268, 216-222; discussion 222-226, 242-253.

Thapar, A., Langley, K., Fowler, T., Rice, F., Turic, D., Whittinger, N., Aggleton, J., Van den Bree, M., Owen, M., O'Donovan, M., and Catechol, O. (2005). Methyltransferase gene variant and birth weight predict earlyonset antisocial behavior in children with attention-deficit/hyperactivity disorder. Arch. Gen. Psychiatry 62, 1275-1278.

Tremblay, R. E., Pihl, R. O., Vitaro, F., and Dobkin, P. L. (1994). Predicting early onset of male antisocial behavior from preschool behavior. Arch. Gen. Psychiatry 51, 732-739.

Trouton, A., Spinath, F. M., and Plomin, R. (2002). Twins early development study (TEDS): a multivariate, longitudinal genetic investigation of language, cognition and behavior problems in childhood. Twin Res. 5, 444-448.

Tuvblad, C., Raine, A., Zheng, M., and Baker, L. A. (2009). Genetic and environmental stability differs in reactive and proactive aggression. Aggress. Behav. 35, 437-452.

Unis, A. S., Cook, E. H., Vincent, J. G., Gjerde, D. K., Perry, B. D., Mason, C., and Mitchell, J. (1997). Platelet serotonin measures in adolescents with conduct disorder. Biol. Psychiatry 553-559.

Van Bokhoven, I., van Goozen, S. H., van Engeland, H., Schaal, B., Arseneault, L., Séguin, J. R., Assaad, J.M., Nagin, D. S., Vitaro, F., and Tremblay, R. E. (2006). Salivary testosterone and aggression, delinquency, and social dominance in a population-based longitudinal study of adolescent males. Horm. Behav. 50, 118-125.

Van de Wiel, N. M., van Goozen, S. H., Matthys, W., Snoek, H., and van Engeland, H. (2004). Cortisol and treatment effect in children with disruptive behavior disorders: a preliminary study. J. Am. Acad. Child Adolesc. Psychiatry 43, 1011-1018.

Van Goozen, S. H., Fairchild, G. (2009). "The neuroendocrinology of antisocial behavior," in The Neurobiological Basis of Violence: Science and Rehabilitation, eds S. Hodgins, E. Viding, and A. Plodowski (New York: Oxford University Press), 168-200.

Van Goozen, S. H., Matthys, W., CohenKettenis, P. T., Buitelaar, J. K., and van Engeland, H. (2000). Hypothalamicpituitary-adrenal axis and autonomic nervous system activity in disruptive 
children and matched controls. J. Am. Acad. Child Adolesc. Psychiatry 39, 1438-1445.

Van Goozen, S. H., Matthys, W., CohenKettenis, P. T., Thijssen, J. H., and van Engeland, H. (1998a). Adrenal androgens and aggression an conduct disorder prepubertal boys and normal controls. Biol. Psychiatry 43, 156-158.

Van Goozen, S. H., Matthys, W., CohenKettenis, P. T., Gispen-de Wied, C., Wiegant, V. M., and van Engeland, H. (1998b). Salivary cortisol and cardiovascular activity during stress in oppositional-defiant disorder boys and normal controls. Biol. Psychiatry $43,531-539$.

Van Goozen, S. H., Matthys, W., CohenKettenis, P. T., Westenberg, H., and van Engeland, H. (1999). Plasma monoamine metabolites and aggression: two studies of normal and oppositional defiant disorder children. Eur. Neuropsychopharmacol. 9, 141-147.

Van Honk, J., Poper, J., Schutter, D. (2005). Testosterone reduces unconscious fear but not consciously experienced anxiety: implications for the disorders of fear and anxiety. Biol. Psychiatry 58, 218-225,

Vanyukov, M. M., Moss, H. B., Plail, J. A., Blackson, T., Mezzich, A. C., and Tarter, R. E. (1993). Antisocial symptoms in preadolescent boys and in their parents: associations with cortisol. Psychiatry Res 46, 9-17.

Veit, R., Flor, H., Erb, M., Hermann, C., Lotze, M., Grodd, W., and Birbaumer, N. (2002). Brain circuits involved in emotional learning in antisocial behavior and social phobia in humans. Neurosci. Lett. 328, 233-236.

Viding, E., Blair, R. J. R., Moffitt, T. E., and Plomin, R. (2005). Evidence for substantial genetic risk for psychopathy in 7-year-olds. J. Child. Psychol. Psychiatry 46, 592-597.

Viding, E., Fontaine, N. M., Oliver, B. R., and Plomin, R. (2009). Negative parental discipline, conduct problems and callous-unemotional traits: monozygotic twin differences study. Br. J. Psychiatry 195, 414-419.

Virkunnen, M., Goldman, D., Nielsen, D. A., and Linnoila, M. (1995). Low brain serotonin turnover rate (low CSF 5-HIAA) and impulsive violence. J. Psychiatry Neurosci. 20, 271-275.

Vitaro, F., Barker, E. D., Boivin, M., Brendgen, M., and Tremblay, R. E. (2006). Do early difficult temperament and harsh parenting differentially predict reactive and proactive aggression? J. Abnorm. Child Psychol. 34, 681-691.

Vitaro, F., and Brendgen, M. (2002). "Proactive and reactive aggression: a developmental perspective," in Developmental Origins of Aggression, eds R. E. Tremblay, W. W. Hartup, and J. Archer, (New York, NY: Guilford Press), 178-201.

Vitaro, F., and Brendgen, M. (2005). "Proactive and reactive aggression: a developmental perspective," in Developmental Origins of Aggression, eds R. E. Tremblay, W.W. Hartup, and
J. Archer (New York, NY: Guilford Press), 178-201.

Vitaro, F., Gendreau, P. L., Tremblay, R. E., and Oligny, P. (1998). Reactive and proactive aggression differentially predict later conduct problems. J. Child. Psychol. Psychiatry 39, 377-385.

Vitiello, B., and Stoff, D. M. (1997). Subtypes of aggression and their relevance to child psychiatry. J. Am. Acad. Child Adolesc. Psychiatry 36, 307-315.

Volavka, J. (1990). Aggression, electroencephalography, and evokes potentials: a critical review. Neuropsychiatry Neuropsychol. Behav. Neurol. 3, 249-259.

Webster-Stratton, C., Reid, M. J., and Hammond, M. (2004). Treating children with early-onset conduct problems: intervention outcomes for parent, child, and teacher training.J. Clin. Child Adolesc. Psychol. 33, 105-124.

Webster-Stratton, C., and Taylor, T. (2001). Nipping early risk factors in the bud: preventing substance abuse, delinquency, and violence in adolescence through interventions targeted at young children (0-8 years). Prev. Sci. 2, 165-192.

Wirth, M. M., and Schultheis, O. C. (2007). Basal testosterone moderates response to anger faces in humans. Physiol. Behav. 90, 496-505.

World Health Organisation. (2007). The ICD-10 Classification of Mental and Behavioural Disorders: Diagnostic Criteria for Research. Geneva: World Health Organisation.
Wüst, S., Federenko, I., Hellhammer, D. H., and Kirschbaum, C. (2000). Genetic factors, perceived chronic stress, and the free cortisol response to awakening. Psychoendocrinology 25, 707-720.

Yang, Y., Raine, A., Lencz, T., Bihrle, S., LaCasse, L., and Colletti, P. (2005). Volume reduction in prefrontal gray matter in unsuccessful criminal psychopaths. Biol. Psychiatry 57, 1103-1108.

Conflict of Interest Statement: The authors declare that the research was conducted in the absence of any commercial or financial relationships that could be construed as a potential conflict of interest.

Received: 20 April 2010; paper pending published: 10 May 2010; accepted: 30 June 2010; published online: 12 October 2010. Citation: Stadler C, Poustka F and Sterzer $P$ (2010) The heterogeneity of disruptive behavior disorders - implications for neurobiological research and treatment. Front. Psychiatry 1:21. doi: 10.3389/ fpsyt.2010.00021

This article was submitted to Frontiers in Child and Neurodevelopmental Psychiatry, a specialty of Frontiers in Psychiatry.

Copyright (๑) 2010 Stadler, Poustka and Sterzer. This is an open-access article subject to an exclusive license agreement between the authors and the Frontiers Research Foundation, which permits unrestricted use, distribution, and reproduction in any medium, provided the original authors and source are credited. 